\section{Stem anatomy supports Arabidopsis thaliana as a model for insular woodiness}

\section{Introduction}

Arabidopsis thaliana (L.) Heynh. (Brassicaceae) is a small annual distributed in open and disturbed habitats of temperate Eurasia (O'Kane \& Al-Shehbaz, 1997). It has generally been accepted that the major part of its aboveground inflorescence stem does not show secondary growth under normal growth conditions. However, treatments that stop or delay flower development, such as manual clipping of flowers (Lev-Yadun, 1994) and changing of the photoperiod from long to short days (Chaffey et al., 2002), stimulate and prolong to a limited extent cambial activity in roots, hypocotyls, rosette-level short stems and/or the basal part of inflorescence stems in the Columbia (Col) wild-type accession. Likewise, other perturbations such as applying weights to the inflorescence stem (Ko et al., 2004) or intra-tissue tensions (Sehr et al., 2010) have a similar stimulating effect on the cambium. There is also extensive literature on plant hormones functioning as an essential stimulus in cambium initiation and activity, especially auxin (Aloni, 1987; Little et al., 2002; Agusti et al., 2011) and cytokinin (Matsumoto-Kitano et al., 2008; Hejátko et al., 2009). In addition, other hormones such as ethylene (Love et al., 2009), gibberellins (Björklund et al., 2007) and jasmonate (Sehr et al., 2010) can also stimulate secondary growth. Consequently, modulated expression of wood-forming genes still present in A. thaliana can cause a significant increase in wood formation (Oh et al., 2003; Ko et al., 2004; Groover, 2005). Interestingly, at least some key genes associated with the shoot apical meristem are also expressed in the cambial zone during secondary growth (Schrader et al., 2004), which might explain why there is a strong evolutionary pressure for these wood-inducing genes to be maintained in herbaceous plants (Spicer \& Groover, 2010).

Compared with trees and even normal-sized shrubs, the amount of secondary growth in the inflorescence stems of the Col accession remains limited to only a few cell layers, and this hampers our understanding of the regulatory process involved in wood formation when $A$. thaliana is used as a model plant (Li et al., 2006). Consequently, the search for woodier $A$. thaliana mutants, such as cov1 (continuous vascular ring) (Parker et al., 2003) and hca (high cambial activity) (Pineau et al., 2005), and woodier transgenic plants over-expressing AtHB8 (Arabidopsis thaliana homeobox) (Baima et al., 2001) has had the aim of unraveling the genetic mechanism for wood formation. We recently described a double mutant (in the Col background) showing wood development throughout all stems and to a much larger extent than any $A$. thaliana mutant described to date (Melzer et al., 2008). In this double mutant, two MADS box genes, SUPPRESSOR OF OVEREXPRESSION OF CONSTANS 1 (SOC1) and FRUITFULL (FUL), which both play a role in flowering time control, were knocked out. SOC1 integrates signals derived from photoperiod (Abe et al., 2005; Wigge et al., 2005), temperature (Searle et al., 2006), gibberellins and agerelated signals (Wang et al., 2009; Lee \& Lee, 2010), while FUL shows only a mild flowering time effect and plays additional roles in floral meristem identity, and carpel and leaf development (Ferrandiz et al., 2000; Teper-Bamnolker \& Samach, 2005). In soc1 ful double mutants, flowering time is synergistically delayed compared with single mutants, indicating that both genes have redundant roles in flowering time control. Besides the shrub-like habit, the double mutants show a combination of perennial-like features, such as a prolonged plant lifetime of up to 18 months, the co-occurrence of active vegetative and reproductive meristems, and recurrent flowering cycles (Melzer et al., 2008).

Woody soc1 ful double mutants have been created in a Col background, implying that the double mutant is derived from an herbaceous $\mathrm{Col}$ accession and must therefore be called secondarily woody. There is ample molecular phylogenetic evidence for a herbaceous ancestry of secondarily woody taxa in many flowering plant families occurring on islands (therefore often referred to as insular woodiness; for example, Böhle et al., 1996; Lee et al., 2005) or island-like regions such as tropical mountain peaks (Jordon-Thaden et al., 2010). Furthermore, there are also wood anatomical characters - so-called paedomorphic features - that can be used to identify secondary or insular woodiness (Carlquist, 1962, 2009; Lens et al., 2009; Dulin \& Kirchoff, 2010). Paedomorphic or juvenile wood features resemble characters of the primary xylem that are protracted into the more mature secondary xylem (= wood) of secondarily woody species. Likewise, delayed periderm formation is sometimes considered a paedomorphic bark feature (e.g. Cumbie, 1983), although cortical photosynthesis in primarily woody trees can also lead to delayed periderm formation.

The objectives of this study were: to describe the stem anatomy of the woody $A$. thaliana mutant (Supporting Information Notes S1); to look for characters in the woody mutant stem that point to a herbaceous descent; and to compare the wood anatomy of $A$. thaliana with that of other members of Brassicaceae that develop into woody shrubs in their natural environment (Carlquist, 1971; Kowal \& Cutler, 1974; Schweingruber, 2006). A strong wood anatomical similarity between the soc 1 ful double mutant and other woody Brassicaceae would provide evidence that the induced wood formation in the mutant is triggered by the 'normal' genetic pathway, and this would reinforce the idea that A. thaliana is a valid model organism with which to study the genetic mechanism behind wood formation in insular eudicots. 
New

\section{The boundary between herbaceousness and woodiness is vague}

We found that basal inflorescence stems of Col plants expressed a limited amount of cambial activity in the intrafascicular regions (Fig. 1a,c,e,g), and started to develop an incomplete cambium ring in the interfascicular regions when inflorescence stems were between 15 and $20 \mathrm{~cm}$ in length (Fig. 1e). This limited secondary growth has been described before, although intraspecific variation exists: some studies have shown a whole ring of vascular cambium producing a few cell layers of wood in the basal stem parts, and cambial activity may reach up to $7 \mathrm{~mm}$ above the basal rosette in 30-cm-long inflorescence stems of the $\mathrm{Col}$ accession (Sehr et al., 2010). Nonetheless, this increased cambial activity remains limited compared with the woodier socl ful mutant (Fig. 1f,h) and can be linked to the more juvenile stages (Fig. 1b,d). The presence of secondary tissues in the Col accession agrees with numerous anatomical studies on herbaceous plants showing a continuous range of limited wood formation in basal stem parts (cf. Dulin \& Kirchoff, 2010; references cited therein). Therefore, the boundary between the terms 'herbaceousness' and 'woodiness' is fuzzy from an anatomical point of view.

While the Col accession showed negligible wood development in the inflorescence stems, the double mutant can be considered a truly woody shrub (Melzer et al., 2008). However, roots of the double mutant did not show an increase in secondary growth to the same extent as in stems, suggesting that other key regulatory genes are involved in wood formation within roots. The increasing difference in wood development with age between the aboveground and underground tissues of the double mutants does probably inhibit the growth of these plants for several years.

\section{Striking wood anatomical similarity between A. thaliana and other members of Brassicaceae}

The microscopic wood structure of the soc1 ful double mutant was found to be remarkably similar to that of the other (secondarily) woody Brassicaceae investigated (Figs 2, S1 and Notes S1),
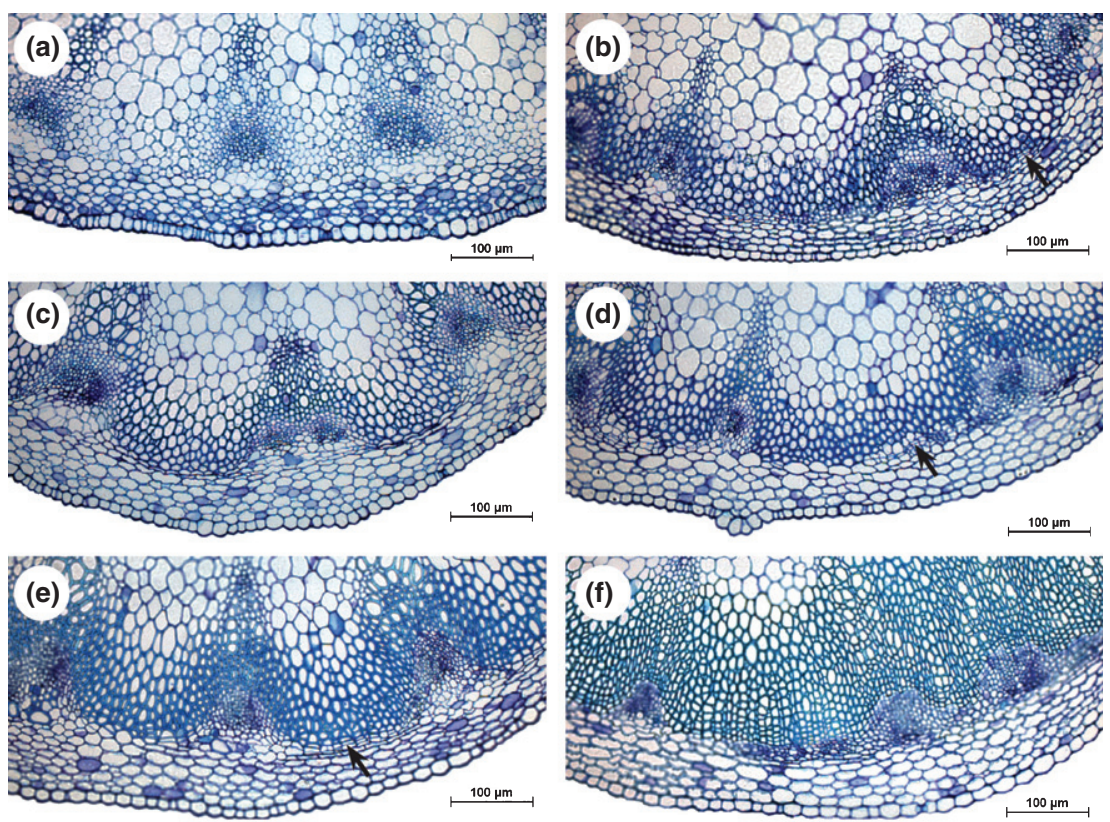

(g)

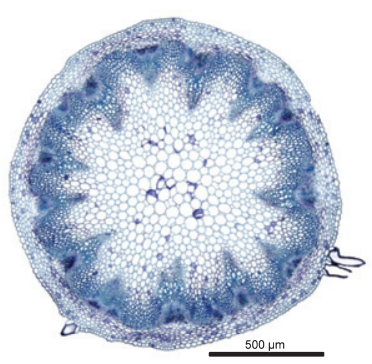

(h)

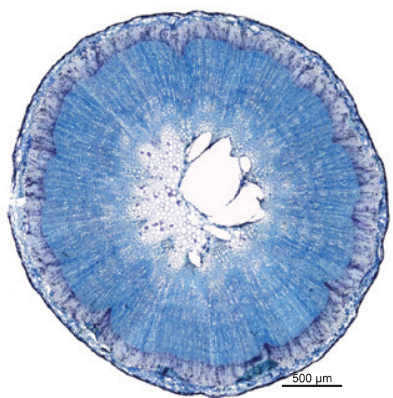

Fig. 1 Transverse sections of a kinetic series representing the Arabidopsis thaliana Columbia (Col) accession (a, c, e, g) and the SUPPRESSOR OF OVEREXPRESSION OF CONSTANS 1/FRUITFULL ( $\operatorname{soc} 1 \mathrm{ful}$ ) double mutant (b, $\mathrm{d}, \mathrm{f}, \mathrm{h}$ ); plants were grown on soil in growth chambers in long-day conditions ( $16 \mathrm{~h}$ light : $8 \mathrm{~h}$ dark) at $22^{\circ} \mathrm{C}$, and sectioned using LR White embedding (hard grade; London Resin, Reading, UK). (a, b) Sections made at $5 \mathrm{~cm}$ height and at the base $(c, d)$ of a 6 - $\mathrm{cm}$-long inflorescence stem; $(e, f)$ sections made at the base of a 20-cm-long inflorescence stem; ( $g$, h) sections made at the base of fully mature stems. (a) No secondary growth visible. (b) Interfascicular cambium is forming (arrow). (c) No secondary growth visible. (d) Interfascicular cambium (arrow) producing a few layers of new cells; the wood cylinder is still incomplete. (e) Interfascicular cambium is forming (arrow). (f) The complete wood cylinder has been formed. (g) Overview of a mature Col stem with negligible secondary growth. (h) Overview of a fully mature soc1 ful stem illustrating extensive secondary growth. 

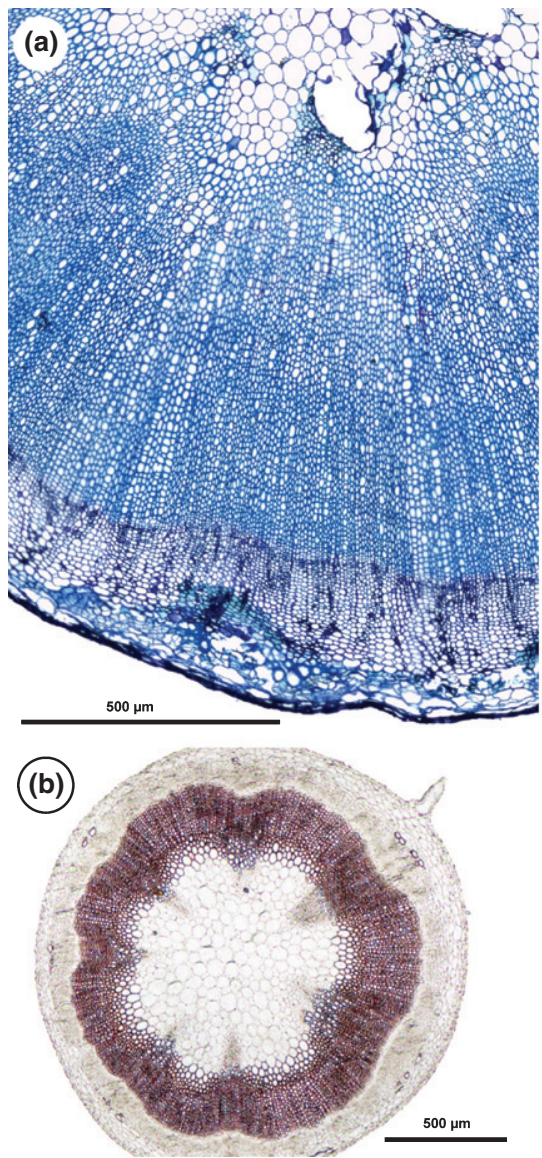
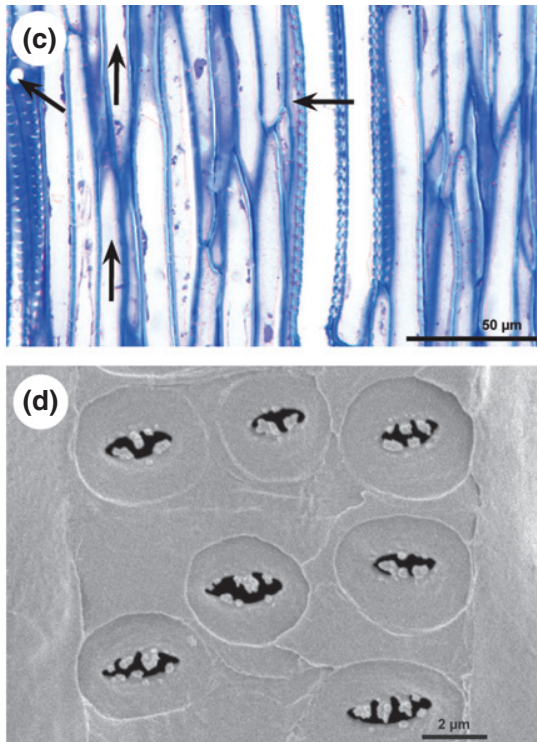

(e)

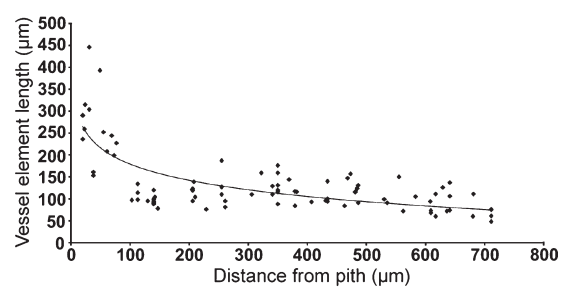

Fig. 2 Selected anatomical characters in mature wood of the Arabidopsis thaliana SUPPRESSOR OF OVEREXPRESSION OF CONSTANS 1/FRUITFULL (soc1 ful) double mutant: ( $a, b)$ transverse sections, (c) a radial section, and (d) a tangential section. (a) Detail showing the absence of rays and limited periderm formation. (b) A relatively young stem stained with phloroglucinol showing lignified wood. (c) Wood composed of narrow vessels with simple perforations (oblique arrow), fibres (vertical arrows), and axial parenchyma (horizontal arrow). (d) Vestured intervessel pits. (e) Flat length-on-age curve of vessel elements.

showing notably short vessel elements (usually $<200 \mu \mathrm{m}$ ), exclusively simple vessel perforations (Figs $2 \mathrm{c}, \mathrm{S} 1 \mathrm{~b}$ ), solitary vessels in combination with vessels arranged in (often radial) multiples, vestured intervessel pitting (Figs 2d, S1d), axial parenchyma adjacent to vessels, and fibres with simple pits or with reduced pit borders (Carlquist, 1971; Kowal \& Cutler, 1974; Schweingruber, 2006). Noteworthy was the presence of vestured pits in the double mutant and other woody Brassicaceae genera. Within the order Brassicales, vestures are present in only a few families, including Brassicaceae and its two most closely related families, Capparaceae and Cleomaceae, which re-emphasizes the informative phylogenetic value of vestured pits at high taxonomic levels (Jansen et al., 2001, 2004). One of the minor anatomical differences in wood structure between soc1 ful mutants and other woody Brassicaceae was the absence of rays (Fig. 2a) vs the presence of multiseriate rays, including predominantly square to erect ray cells (Fig. S1a,c). This distinction is only a minor one, however, and has been observed in many secondarily woody taxa (Carlquist, 1962, 2009; Lens et al., 2007, 2009). Furthermore, it is known that rayless species with relatively thin stems, such as A. thaliana, may develop rays at a later stage when the stem reaches larger diameters (Carlquist, 1970).
The fact that the wood anatomical characters of the A. thaliana double mutant were nearly identical to the anatomy of other woody Brassicaceae strengthens our assumption that inactivation of both the SOC1 and FUL genes triggers the 'normal' pathway leading to increased wood formation. The observed anatomical similarity supports the hypothesis that the genetic mechanisms underlying the developmental processes of wood development may potentially be highly conserved between woody and herbaceous plants (Kirst et al., 2003; Schrader et al., 2004; Groover, 2005; Spicer \& Groover, 2010), implying that knock-out mutants would be perfect models for secondary growth and wood developmental research (Chaffey et al., 2002; Nieminen et al., 2004).

\section{Paedomorphic wood features in the soc1 ful mutant and other woody Brassicaceae indicate herbaceous descent}

A second strong anatomical argument for the activation of the 'normal' genetic pathway leading to extensive wood formation in the double mutant is the expected occurrence of two paedomorphic wood features, that is, the absence of rays (Figs 1h, 2a) and 
the continuously decreasing length-on-age curve of vessel elements (Fig. 2e); the delayed periderm formation in the double mutant (Fig. 2a) might be considered a third paedomorphic bark feature, and is also present in some woody Brassicaceae (Fig. S1a). According to Carlquist (1962, 2009), the most convincing wood character that identifies secondarily woody species is the flat or continuously decreasing length-on-age-curve of vessel elements: after a strong decrease in vessel element length in the primary xylem and first formed secondary xylem from 450 to $150 \mu \mathrm{m}$, the length stabilizes and shows an extremely low value of $c .100 \mu \mathrm{m}$ (Fig. 2e). A similar situation was observed in the three other woody Brassicaceae species studied (Fig. S1e). Although we are aware that the maximal stem diameter in our double mutant might not be large enough $(5 \mathrm{~mm})$ to reach full maturity in its wood structure, we consider Fig. 2(e) a representative length-on-age curve. This is based on Bailey (1920), who demonstrated that the range of vessel elements remains almost constant in the secondary xylem in species that are characterized by so-called derived vessel elements, that is, very short vessel elements $(<300 \mu \mathrm{m}$ on average) combined with exclusively simple perforations (cf. Carlquist, 1962). A hydraulic explanation of the variation in vessel element length during secondary growth has not been forthcoming: it is assumed that the length of entire vessels is more important in the water transport mechanism of plants, and greatly overwhelms the importance of vessel element length (e.g. Lens et al., 2011).

Although Brassicaceae are a predominantly herbaceous family, truly woody genera - representing shrubs and even lianas - are scattered over at least 12 tribes of all major lineages in the latest molecular phylogenies (Beilstein et al., 2006; Franzke et al., 2009, 2011; Couvreur et al., 2010; Warwick et al., 2010). This supports our observation of paedomorphic wood features indicating secondary woodiness in Brassicaceae (Appel \& Al-Shehbaz, 2003). Also the more fine-scale molecular phylogenies at the genus level demonstrate that the (secondarily) woody species are derived from their herbaceous relatives in, for instance, Crambe (Francisco-Ortega et al., 1999), Lepidium (Mummenhoff et al., 2001) and Draba (Jordon-Thaden et al., 2010).

\section{Conclusions}

The soc1 ful double mutant of $A$. thaliana produced substantial secondary growth throughout all aboveground stems, whereas in the Col accession only a few cell layers of wood were produced at the base of old stems. This increased wood formation may be linked to inactivation of the flowering time genes SOC1 and FUL (Melzer et al., 2008). These two genes could play a crucial regulatory role in triggering genetic mechanisms that lead to insular woodiness outside $A$. thaliana, and this 'simple' two-gene loss could explain why many nonrelated herbaceous families have independently evolved into woody insular lineages throughout the world. However, SOC1 and FUL might not be the only suppressors of cambium formation; other upstream, downstream or parallel-acting (positive or negative) regulators could be even more important. Therefore, it is evident that many missing pieces of this intriguing genetic puzzle leading to insular woodiness in eudicots need to be found before we can better understand one of the most fascinating developmental aspects of plants (cf. Lev-Yadun, 1994; Chaffey et al., 2002; Nieminen et al., 2004).

\section{Acknowledgements}

S.M. was a senior fellow (SF/10/007) of the Research Fund of the K.U. Leuven.

\section{Frederic Lens ${ }^{1 *}$, Erik Smets ${ }^{1,2}$ and Siegbert Melzer ${ }^{2,3 *}$}

${ }^{1}$ Netherlands Centre for Biodiversity Naturalis (Section NHN), Leiden University, PO Box 9514, NL-2300 RA Leiden, The Netherlands; ${ }^{2}$ Laboratory of Plant Systematics, Institute of Botany and Microbiology, Kasteelpark Arenberg 31 Box 2437, K.U. Leuven, BE-3001 Leuven, Belgium; ${ }^{3}$ Present address: Plant Breeding Institute, Christian-Albrechts-University Kiel, Am Botanischen Garten 1-9, D-24118 Kiel, Germany $\left({ }^{*}\right.$ Authors for correspondence: Frederic Lens tel +31715273570; email lens@nhn.leidenuniv.nl; Siegbert Melzer tel +49 431880 3345; emails.melzer@plantbreeding.uni-kiel.de)

\section{References}

Abe M, Kobayashi Y, Yamamoto S, Daimon Y, Yamaguchi A, Ikeda Y, Ichinoki H, Notaguchi M, Goto K, Araki T. 2005. FD, a bZIP protein mediating signals from the floral pathway integrator $F T$ at the shoot apex. Science 309: 1052-1056.

Agusti J, Lichtenberger R, Schwarz M, Nehlin L, Greb T. 2011.

Characterization of transcriptome remodeling during cambium formation identifies $M O L 1$ and $R U L 1$ as opposing regulators of secondary growth. PLoS Genetics 7: e1001312.

Aloni R. 1987. Differentiation of vascular tissues. Annual Review of Plant Physiology 38: 179-204.

Appel O, Al-Shehbaz IA. 2003. Cruciferae. In: Kubitzki K, Bayer C, eds. The families and genera of flowering plants. Berlin, Germany; Heidelberg, Germany; New York, NY, USA: Springer Verlag, 5: 75-174.

Bailey IW. 1920. The cambium and its derivative tissues. II. Size variations of cambial initials in gymnosperms and angiosperms. American Journal of Botany 7: 355-367.

Baima S, Possenti M, Matteucci A, Wisman E, Altamura MM, Ruberti I, Morelli G. 2001. The Arabidopsis ATHB-8 HD-Zip protein acts as a differentiation-promoting transcription factor of the vascular meristems. Plant Physiology 126: 643-655.

Beilstein MA, Al-Shehbaz IA, Kellogg EA. 2006. Brassicaceae phylogeny and trichome evolution. American Journal of Botany 93: 607-619.

Björklund S, Antti H, Uddestrand I, Moritz T, Sundberg B. 2007. Cross-talk between gibberellin and auxin in development of Populus wood: gibberellin stimulates polar auxin transport and has a common transcriptome with auxin. The Plant Journal 52: 499-511.

Böhle UR, Hilger HH, Martin WF. 1996. Island colonization and evolution of the insular woody habit in Echium L. (Boraginaceae). Proceedings of the National Academy of Sciences, USA 93: 11740-11745.

Carlquist S. 1962. A theory of paedomorphosis in dicotyledonous woods. Phytomorphology 12: 30-45.

Carlquist S. 1970. Wood anatomy of insular species of Plantago and the problem of raylessness. Bulletin of the Torrey Botanical Club 97: 353-361.

Carlquist S. 1971. Wood anatomy of Macaronesian and other Brassicaceae. Aliso 7: 365-384.

Carlquist S. 2009. Xylem heterochrony: an unappreciated key to angiosperm origin and diversifications. Botanical Journal of the Linnean Society 161: 26-65. 
Chaffey N, Cholewa E, Regan S, Sundberg B. 2002. Secondary xylem development in Arabidopsis: a model for wood formation. Physiologia Plantarum 114: 594-600.

Couvreur TLP, Franzke A, Al-Shebahz IA, Bakker FT, Koch MA, Mummenhoff K. 2010. Molecular phylogenetics, temporal diversification, and principles of evolution in the mustard family (Brassicaceae). Molecular Biology and Evolution 27: 55-71.

Cumbie BG. 1983. Developmental changes in the wood of Bocconia vulcanica Donn. Smith. International Association of Wood Anatomists Bulletin new series 4: 131-140.

Dulin MW, Kirchoff BK. 2010. Paedomorphosis, secondary woodiness, and insular woodiness in plants. Botanical Review 76: 405-490.

Ferrandiz C, Gu Q, Martienssen R, Yanofsky M. 2000. Redundant regulation of meristem identity and plant architecture by Fruitfull, Apetala1 and Cauliflower. Development 127: 725-734.

Francisco-Ortega J, Fuertes-Aguilar J, Gómez-Campo C, Santos-Guerra A, Jansen RK. 1999. Internal transcribed spacer sequence phylogeny of Crambe L. (Brassicaceae): molecular data reveal two Old World disjunctions. Molecular Phylogenetics and Evolution 11: 361-380.

Franzke A, German D, Al-Shebahz IA, Mummenhoff K. 2009. Arabidopsis ties: molecular phylogeny and age estimates in Brassicaceae. Taxon 58: 425-437.

Franzke A, Lysak MA, Al-Shehbaz IA, Kocj MA, Mummenhoff K. 2011. Cabbage family affairs: the evolutionary history of Brassicaceae. Trends in Plant Science 16: 108-116.

Groover AT. 2005. What genes make a tree a tree? Trends in Plant Science 10: 210-214.

Hejátko J, Ryu H, Kim G-T, Dobešová R, Choi S, Choi SM, Souček P, Horák J, Pekárová B, Palme K et al. 2009. The histidine kinases CYTOKINININDEPENDENT 1 and ARABIDOPSIS HISTIDINE KINASE 2 and 3 regulate vascular tissue development in Arabidopsis shoots. The Plant Cell 21: 2008-2021.

Jansen S, Baas P, Gasson P, Lens F, Smets E. 2004. Variation in xylem structure from tropics to tundra: evidence from vestured pits. Proceedings of the National Academy of Sciences, USA 101: 8833-8837.

Jansen S, Baas P, Smets E. 2001. Vestured pits: their occurrence and systematic importance in eudicots. Taxon 50: 135-167.

Jordon-Thaden I, Hase I, Al-Shebahz I, Koch MA. 2010. Molecular phylogeny and systematics of the genus Draba (Brassicaceae) and identification of its closest related genera. Molecular Phylogenetics and Evolution 55: 524-540.

Kirst M, Johnson AF, Baucom C, Ulrich E, Hubbard K, Staggs R, Paule C, Retzel E, Whetten R, Sederoff R. 2003. Apparent homology of expressed genes from wood-forming tissues of loblolly pine (Pinus taeda L.) with Arabidopsis thaliana. Proceedings of the National Academy of Sciences, USA 100: 7383-7388.

Ko JH, Han KH, Yang J. 2004. Plant body weight-induced secondary growth in Arabidopsis and its transcription phenotype revealed by whole-transcriptome profiling. Plant Physiology 135: 1069-1083.

Kowal E, Cutler DF. 1974. The wood anatomy of Schouwia purpurea subsp. arabica and Fabrisinapis fruticosus (Cruciferae). Kew Bulletin 30: 503-507.

Lee C, Kim S-C, Lundy K, Santos-Guerra A. 2005. Chloroplast DNA phylogeny of the woody Sonchus alliance (Asteraceae: Sonchinae) in the Macaronesian islands. American Journal of Botany 92: 2072-2085.

Lee J, Lee I. 2010. Regulation and function of SOC1, a flowering pathway integrator. Journal of Experimental Botany 61: 2247-2254.

Lens F, Groeninckx I, Smets E, Dessein S. 2009. Woodiness within the Spermacoceae-Knoxieae alliance: retention of the basal woody condition in Rubiaceae or recent innovation? Annals of Botany 103: 1049-1064.

Lens F, Schönenberger J, Baas P, Jansen S, Smets E. 2007. The role of wood anatomy in phylogeny reconstruction of Ericales. Cladistics 23: 229-254.

Lens F, Sperry JS, Christman MA, Choat B, Rabaey D, Jansen S. 2011. Testing hypotheses that link wood anatomy to cavitation resistance and hydraulic conductivity in the genus Acer. New Phytologist 190: 709-723.

Lev-Yadun S. 1994. Induction of sclereid differentiation in the pith of Arabidopsis thaliana (L.) Heynh. Journal of Experimental Botany 45: 1845-1849.

Li L, Lu S, Chiang V. 2006. A genomic and molecular view of wood formation. Critical Reviews in Plant Sciences 25: 215-233.
Little CHA, MacDonald JE, Olsson O. 2002. Involvement of indole-3-acetic acid in fascicular and interfascicular cambial growth and interfascicular extraxylary fibre differentiation in Arabidopsis thaliana inflorescence stems. International Journal of Plant Sciences 163: 519-529.

Love J, BJörklund S, Vahala J, Hertzberg M, Kangasjärvi J, Sundberg B. 2009. Ethylene is an endogenous stimulator of cell division in the cambial meristem of Populus. Proceedings of the National Academy of Sciences, USA 106: 5984-5989.

Matsumoto-Kitano M, Kusumoto T, Tarkowski P, Kinoshita-Tsujimura K, Václaviková K, Miyawaki K, Kakimoto T. 2008. Cytokinins are central regulators of cambial activity. Proceedings of the National Academy of Sciences, USA 105: 20027-20031.

Melzer S, Lens F, Gennen J, Vanneste S, Rhode A, Beeckman T. 2008. Flowering time genes modulate meristem determinacy and growth form in Arabidopsis. Nature Genetics 40: 1489-1492.

Mummenhoff K, Brüggemann H, Bowman JL. 2001. Chloroplast DNA phylogeny of Lepidium (Brassicaceae). American Journal of Botany 88 2051-2063.

Nieminen KM, Kauppinen L, Helariutta Y. 2004. A weed for wood? Arabidopsis as a genetic model for xylem development. Plant Physiology 135: 635-659.

Oh S, Park S, Han KH. 2003. Transcriptional regulation of secondary growth in Arabidopsis thaliana. Journal of Experimental Botany 54: 2709-2722.

O'Kane SL Jr, Al-Shehbaz IA. 1997. A synopsis of Arabidopsis (Brassicaceae). Novon 7: 323-327.

Parker G, Schofield R, Sundberg B, Turner S. 2003. Isolation of COV1, a gene involved in the regulation of vascular patterning in the stem of Arabidopsis. Development 130: 2130-2148.

Pineau C, Freydier A, Ranocha P, Jauneau A, Turner S, Lemonnier G, Renou JP, Tarkowski P, Sandberg G, Jouanin L et al. 2005. hca: an Arabidopsis mutant exhibiting unusual cambial activity and altered vascular patterning. The Plant Journal 44: 271-289.

Schrader J, Nilsson J, Mellerowicz E, Berglund A, Nilsson P, Hertzberg M, Sandberg G. 2004. A high-resolution transcript profile across the woodforming meristem of poplar identifies potential regulators of cambial stem identity. Plant Cell 16: 2278-2292.

Schweingruber FH. 2006. Anatomical characteristics and ecological trends in the xylem and phloem of Brassicaceae and Resedaceae. International Association of Wood Anatomists Journal 27: 419-442.

Searle I, He Y, Turck F, Vincent C, Fornara F, Kröber S, Amasino RA, Coupland G. 2006. The transcription factor $F L C$ confers a flowering response to vernalization be repressing meristem competence and systemic signalling in Arabidopsis. Genes \& Development 20: 898-912.

Sehr EM, Agusti J, Lehner R, Farmer EE, Schwarz M, Greb T. 2010. Analysis of secondary growth in the Arabidopsis shoot reveals a positive role of jasmonate signaling in cambium formation. The Plant Journal 63: 811-822.

Spicer R, Groover A. 2010. Evolution of development of vascular cambia and secondary growth. New Phytologist 186: 577-592.

Teper-Bamnolker P, Samach A. 2005. The flowering integrator $F T$ regulates SEPALLATA3 and FRUITFULL accumulation in Arabidopsis leaves. Plant Cell 17: 2661-2675.

Wang JW, Czech B, Weigel D. 2009. miR156-regulated SPL transcription factors define an endogenous flowering pathway in Arabidopsis thaliana. Cell 138: 738-749.

Warwick SI, Mummenhoff K, Sauder CA, Koch MA, Al-Shebahz IA. 2010. Closing the gaps: phylogenetic relationships in the Brassicaceae based on DNA sequence data of nuclear ribosomal ITS region. Plant Systematics and Evolution 285: 209-232.

Wigge PA, Kim MC, Jaeger KE, Busch W, Schmid M, Lohmann JU, Weigel D. 2005. Integration of spatial and temporal information during floral induction in Arabidopsis. Science 309: 1056-1059.

\section{Supporting Information}

Additional supporting information may be found in the online version of this article. 
New

Phytologist

Fig. S1 Selected anatomical characters in mature wood of Brassicaceae that become shrubby in their natural environment.

Notes S1 Description of mature wood in the soc1 ful double mutant of Arabidopsis thaliana (Figs 1h, 2).

Please note: Wiley-Blackwell are not responsible for the content or functionality of any supporting information supplied by the authors. Any queries (other than missing material) should be directed to the New Phytologist Central Office.

Key words: Arabidopsis thaliana, Brassicaceae, cambium formation, insular woodiness, model plant, secondary woodiness, wood anatomy, wood formation.

\section{About New Phytologist}

- New Phytologist is an electronic (online-only) journal owned by the New Phytologist Trust, a not-for-profit organization dedicated to the promotion of plant science, facilitating projects from symposia to free access for our Tansley reviews.

- Regular papers, Letters, Research reviews, Rapid reports and both Modelling/Theory and Methods papers are encouraged. We are committed to rapid processing, from online submission through to publication 'as ready' via Early View - our average time to decision is $<25$ days. There are no page or colour charges and a PDF version will be provided for each article.

- The journal is available online at Wiley Online Library. Visit www.newphytologist.com to search the articles and register for table of contents email alerts.

- If you have any questions, do get in touch with Central Office (np-centraloffice@lancaster.ac.uk) or, if it is more convenient, our USA Office (np-usaoffice@ornl.gov)

- For submission instructions, subscription and all the latest information visit www.newphytologist.com 